\title{
Gun violence and media effects: challenges for science and public policy
}

Malte Elson and Christopher J. Ferguson

\begin{abstract}
Summary
In response to the Sandy Hook shooting in December 2012, the White House published an action plan to reduce gun violence that, among other things, calls for research into the relationship with violence in digital games or other media images. We acknowledge the administration's efforts to reduce violent crime in society and their obligation to dedicate resources to matters of public interest, such as media effects. However, research projects launched in the midst of a moral panic bear the risk of introducing bias and distracting from more important issues. Ideological rigidity
\end{abstract}

has repeatedly shaped past research on media violence. Current initiatives could be an opportunity to restore credibility to the field and to engage in a responsible dialogue on media effects. In order to inform public policy, we need to close gaps, both in empirical research and the academic debate, while being alert for potential political and social influences.

\section{Declaration of interest}

None.
Malte Elson (pictured) graduated in psychology and currently works as a research associate in the ERC project 'Social foundations of online gaming' at the Department of Communication, University of Münster. Christopher J. Ferguson is currently serving as Department Chair of Psychology at Stetson University. His work has focused on the effects of media violence on youth violence. He was recently nominated for an Early Career Scientist Award by the American Psychological Association.

Parents and concerned citizens in the USA (and elsewhere) have been following the debate on gun violence elicited by the tragedy at Sandy Hook Elementary School in Newtown, Connecticut, in December 2012. The shooting prompted a controversy regarding causes of violent crime, particularly gun control, mental health reform and portrayals of violence in media, and what governments should do to reduce societal violence. On 16 January 2013, the White House responded ${ }^{1}$ by publishing an action plan to reduce gun violence that includes, among other things, stricter background checks for gun sales and banning of certain weapon types, safety measures for schools, expansive coverage of mental health treatment, and additional efforts in research on the causes and prevention of gun violence. In particular, the plan highlights scrutinising the relationship with violence in digital games or other media images, for which the administration provides an additional \$10 million to the Centers for Disease Control and Prevention. It appears, as it was so aptly put in a recent issue of Science, that the gun control agenda is indeed a call to duty for scientists. $^{2}$

\section{Media violence: evidence v. ideology}

What, then, is the current state of research on violent media effects? The answer to this question is twofold. First, the empirical evidence regarding the impact of media violence on human aggression is fairly mixed, and as such inconclusive. Findings obtained in psychological laboratories seemingly yield the largest effects (although overall still small and inconsistent), yet the singular episodic presentation of stimuli, such as movie clips or $10 \mathrm{~min}$ of gameplay, and artificial measures of aggressive behaviour severely limit the generalisability of many studies. ${ }^{3,4}$ It is important to note as well that many experimental procedures suffer from 'methodological flexibility' problems, ${ }^{5}$ which have been found to result in spuriously high effects. ${ }^{6}$ Many longitudinal studies investigating the consequences of repeated media violence exposure on behaviours support the notion that there is a considerably smaller effect, ${ }^{7}$ or even none at all, ${ }^{8,9}$ while revealing that correlations between violent media use and aggressiveness can be explained by a preference of aggressive individuals for violent media. $^{10}$

The second part of the answer relates to the academic debate on violent media, and how the empirical evidence is (mis)represented by politicians, pundits and scholars. The conclusiveness of existing research on violent game effects is frequently overstated, and indulgence in ideological claims commonly go beyond what scientific evidence supports, posing a risk to the credibility of media effects research. ${ }^{11,12}$ Such claims are particularly inappropriate when causal links between violent game use and increases in actual violent behaviours (or even crimes) are inferred. This has been lamented by the US Supreme Court in its Brown v. Entertainment Merchants Association decision in $2011,{ }^{13}$ and in reviews by the governments of Australia, ${ }^{14}$ and Sweden, ${ }^{15}$ and the US Congress' Task Force on Gun Violence. ${ }^{16}$ If the empirical evidence does not allow for a definite causative statement, why do such claims persist?

\section{Research in a moral panic}

The societal responses and intense debates following tragedies such as the Sandy Hook shooting demonstrate a phenomenon known as moral panic. ${ }^{17}$ In a moral panic, a part of society considers certain behaviours or lifestyle choices of another part to be a significant threat to society as a whole. In this environment, moral beliefs can substantially influence scientific research, and its results are readily used as confirmation for what has been suspected. Researchers involved have a great interest in understanding the mechanisms of aggression to inform efforts at reduction of violent crime in society. Tackling an overt, proximal behaviour such as media use has great merits: attributing violence to manifest displays of media content that are considered immoral has convincing face validity. Moreover, media production and distribution could, in theory, be easily policed and regulated by state agencies. If media were causing harm in society, regulating them would be a fairly easy way of taking action against violent 
crime. However, particularly when exaggerated, warnings about an overt, proximal behaviour such as media use are potentially distracting from covert, distal issues rooted deep within society, such as poverty or inequality. Those problems are major sources of various societal issues, including violent crime, and are usually intangible, providing no ready 'bogeyman' in the parlance of moral panic theory - and are difficult issues to address. Are the funds requested by the Obama administration for research on links between media and crime just part of a newly sparked moral panic?

Not necessarily, but it is an issue the scientific community needs to be alert to. The fact alone that such a research project, even when worded carefully, is launched could be stigmatising and suggestive exactly because this happened in the aftermath of a violent crime. Although media effects only seem to play a secondary role in the President's plan to reduce gun violence, researchers must be aware of potential biases that are conveyed by this call for action. We are not criticising that public funds are spent on media effects research, or advocating that investigations of violence in games should be abandoned altogether. It is, after all, the public that is worried about undesirable consequences of media use, and thus the administration (and the researchers it entrusts) are obliged to strive for answers. But what should we be doing?

\section{We need to close gaps}

There appears to be a discrepancy between what social scientists commonly measure in their laboratories and the behaviours that the public (or policy makers) are concerned about. Past research has usually not been conducted to inform public policy directly, but to advance academic knowledge of fundamental cognitive and behavioural processes in controlled laboratory environments. Consequentially, when policy makers ${ }^{13-16}$ evaluated the empirical evidence, they did not find compelling proof of a link between media use and real-world violent behaviours - they could not, simply because the academic research, with few exceptions, has little bearing on societal violence. Unfortunately, scholars themselves are not always cautious, generalising findings from weak laboratory studies to societal violence in ways that are inappropriate.

A similar discrepancy exists in what media effects scholars find, and what some proclaim it means. The inappropriateness of conjuring a public health crisis cannot be overstated, such as that media violence accounts for up to $30 \%$ of all violence in society, ${ }^{18}$ and that effects of violent games on aggression are as hazardous as smoking effects on lung cancer. ${ }^{19}$ The alarmist manner in which a diffuse concept such as aggression is compared to a serious medical condition such as cancer unnecessarily heats the debate. Moreover, oncology does not have the methodology issues that media effect studies do. Tests for cancer are standardised, reliable and clinically validated: speaking plainly, someone that has lung cancer in a laboratory also has it in the real world. Unfortunately, aggression measures used in laboratory research are far from having such predictive power and are often used in an unstandardised manner. ${ }^{4}$ Finally, lung cancer was not a significant public health problem before smoking became a widespread habit, and its prevalence paralleled that of smoking. ${ }^{20}$ Of course, violent crime has always existed and, if anything, an inverse correlation is observed for violent crime and violent game sales. ${ }^{3}$ Thus, these extreme statements do harm the credibility of media effects research, and hence impede proper debates and adequate policy-making in the best interest of the public. In the light of such extreme statements, how could social science be trusted in informing a public controversy?

The current state of research does not support the notion of an appreciable effect on the general population, but we do acknowledge that under particular circumstances or for subgroups of high-risk individuals it is worth exploring whether there might be adverse effects of violent media. It is the identification of specific risk (and resilience) factors, such as an unfavourable family environment or mental health issues, preferably in prospective studies with actual control groups, in which we see future tasks for media violence researchers. Research should be prepared to conduct more sophisticated analyses of media uses rather than specifically just content issues. We observe that specific individuals may use the same media in very different ways, with very different outcomes. In order to achieve this, scholars should look beyond mechanistic content effect models, and consider differentials in media use by individuals to identify 'healthy' and 'unhealthy' patterns. The understanding how and for what specific reasons adolescents and adults use media may, thus, be more critical than media content itself.

If we are concerned about aggressive behaviour or violent crimes precipitated by violent media, we should consider discontinuing investigations of media uses and effects in samples mostly consisting of college students. Studying media-use patterns of offenders and those who have committed acts of violence against people or property instead could potentially yield highly interesting insights to our understanding of how and when violent media pose a risk.

In moving forward with such a research programme the scientific community must be alert for the intrusion of politics and past problems with ideology in this field. ${ }^{11,12}$ For instance, in a recent call for research, Senator Rockefeller was quoted as saying:

'Recent court decisions demonstrate that some people still do not get it. They believe that violent video games are no more dangerous to young minds than classic literature or Saturday morning cartoons. Parents, pediatricians and psychologists know better. These court decisions show we need to do more and explore ways congress can lay additional groundwork on this issue. This report will be a critical resource in this process.' ${ }^{21}$

Such comments set up undue political pressure on any resulting study.

Further, Senator Rockefeller's call to include the Federal Trade Commission (FTC) and Federal Communication Commission (FCC) in overseeing such research alongside the National Academy of Sciences is a potential conflict of interest given that the FTC and FCC would stand to increase power through any government regulation resulting from research results. The politicised nature of a call such as this is obvious, but the pernicious influence of societal moral panics on media in a broader sense has been, by this point, well documented. ${ }^{3}$ Ten years ago, the journal Nature ${ }^{22}$ called on media researchers to 'tone down the crusading rhetoric until we know more'. Ten years later, we do know more, and what we know now does not suggest that it is time to return to crusading rhetoric. Far from it, it is increasingly time for the scientific community to employ cautious language and act as a voice of reason in the face of societal moral panics. It is imperative that the scientific community remain alert to these issues moving forward.

\section{Boon and bane}

The debate on risks of media violence in academia or the general public is far from being over. The launch of a new research project might advance the field and urge us forward in finding answers. But we must be aware of the dangers of ideologies and biases that have repeatedly shaped past research. This is a great opportunity to restore credibility to the field and to engage in a responsible dialogue on how media effects research can help reducing violent crime, but it also bears the risk of finding the wrong answers for political reasons. 
Malte Elson, Department of Communication, University of Münster, Münster, Germany; Christopher J. Ferguson, Department of Psychology, Stetson University, DeLand, Florida, USA

Correspondence: Malte Elson, Department of Communication, University of Münster, Bispinghof 9-14, 48143 Münster, Germany. Email: malte.elson@ uni-muenster.de

First received 4 Mar 2013, accepted 25 Jun 2013

\section{Funding}

M. E. received funding from the European Union's Seventh Framework Programme (FP7/ 2007-2013) under grant agreement no. 240864 (SOFOGA)

\section{References}

1 The White House. Now is the Time: The President's Plan to Protect our Children and our Communities by Reducing Gun Violence. The White House, 2013.

2 Underwood E. Gun control agenda is a call to duty for scientists. Science 2013; 339: 381-2.

3 Ferguson CJ. Violent video games and the Supreme Court: lessons for the scientific community in the wake of Brown v. Entertainment Merchants Association. Am Psychol 2013; 68: 57-74.

4 Ritter D, Eslea M. Hot sauce, toy guns, and graffiti: a critical account of current laboratory aggression paradigms. Aggres Behav 2005; 31: 407-19.

5 Simmons JP, Nelson LD, Simonsohn U. False-positive psychology: undisclosed flexibility in data collection and analysis allows presenting anything as significant. Psychol Sci 2011; 22: 1359-66.

6 Savage J, Yancey C. The effects of media violence exposure on criminal aggression: a meta-analysis. Crim Justice Behav 2008; 35: 772-91.

7 Willoughby T, Adachi PJC, Good M. A longitudinal study of the association between violent video game play and aggression among adolescents. Dev Psychol 2012; 48: 1044-57.

8 Ferguson CJ, San Miguel C, Garza A, Jerabeck JM. A longitudinal test of video game violence influences on dating and aggression: a 3-year longitudinal study of adolescents. J Psychiat Res 2012; 46: 141-6.
9 Wallenius M, Punamäki R-L. Digital game violence and direct aggression in adolescence: a longitudinal study of the roles of sex, age, and parent-child communication. J Appl Dev Psychol 2008; 29: 286-94.

10 Von Salisch M, Vogelgesang J, Kristen A, Oppl C. Preference for violent electronic games and aggressive behavior among children: the beginning of the downward spiral? Media Psychol 2011; 14: 233-58.

11 Grimes T, Anderson JA, Bergen LA. Media Violence and Aggression: Science and Ideology. Sage, 2008.

12 Hall RCW, Day T, Hall RCW. A plea for caution: violent video games, the Supreme Court, and the role of science. Mayo Clin Proc 2011; 86: 315-21.

13 Brown v. Entertainment Merchants Assn., 564 U.S. (2011).

14 Australian Government Attorney-General's Department. Literature Review on the Impact of Playing Violent Video Games on Aggression. Attorney General's Department, 2010.

15 Statens Medieråd. Våldsamma datorspel och aggression. En översikt av forskningen 2000-2011 [Violent Computer Games and Agggression - An Overview of the Research 2000-2011]. Swedish Media Council, 2011. Available at: http://www.statensmedierad.se/upload/_pdf/ Summery_Violent_Computer_Games.pdf.

16 Gun Violence Prevention Task Force. It's Time to Act: A Comprehensive Plan that Reduces Gun Violence and Respects the 2nd Amendment Rights of Law-Abiding Americans. US House of Representatives, 2013.

17 Gauntlett D. Moving Experiences: Media Effects and Beyond. John Libbey, 2005.

18 Strasburger VC. Go ahead punk, make my day: It's time for pediatricians to take action against media violence. Pediatr 2007; 119: e1398-9.

19 Anderson CA, Berkowitz L, Donnerstein E, Huesmann R, Johnson JD, Linz D, Malamuth NM, et al. The influence of media violence on youth. Psychol Sci Public Interest 2003; 4: 81-110.

20 Doll R. Uncovering the effects of smoking: historical perspective. Stat Meth Med Res 1998; 7: 87-117.

21 Terkel A. Video games targeted by senate in wake of Sandy Hook shooting Huffington Post 2012; 19 December.

22 Nature. A calm view of video violence. Nature 2003; 424: 355. 